POGgiani, S.S.C. et al. Ceratose actínica em cães. PUBVet, Londrina, V. 6, N. 10, Ed. 197, Art. 1320, 2012.

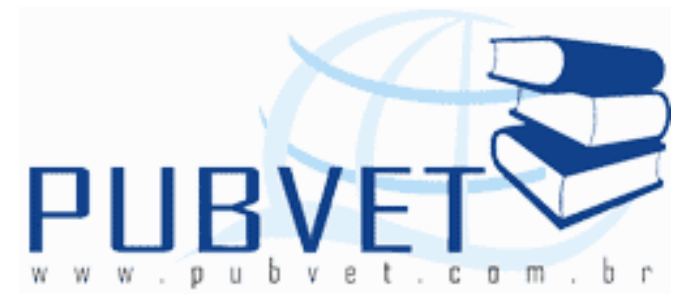

PUBVET, Publicações em Medicina Veterinária e Zootecnia.

\title{
Ceratose actínica em cães
}

Sabrina dos Santos Costa Poggiani ${ }^{1}$; Mário Roberto Hatayde ${ }^{2}$; Juliana Werner ${ }^{3}$;

Renée Laufer Amorim ${ }^{4}$

1. Docente do Departamento de Medicina Veterinária, Faculdades Integradas, União Pioneira de Integração Social.

2. Docente do Departamento de Clínica e Cirurgia Veterinária, Faculdade de Ciências Agrárias e Veterinárias, Universidade Estadual Paulista.

3. Médica Veterinária, Laboratório de Patologia Veterinária Werner \& Werner.

4. Docente do Departamento de Clínica Veterinária, Faculdade de Medicina Veterinária e Zootecnia, Universidade Estadual Paulista.

\section{Resumo}

A ceratose actínica é uma dermatopatia que acomete cães, principalmente de pelame curto e coloração clara. O principal fator etiológico é a exposição excessiva a luz solar, a qual provoca conseqüências imunológicas locais e sistêmicas. Realizou-se um estudo em 10 cães acometidos por ceratose actínica. Os cães foram analisados em relação à raça, ao sexo, à idade, ao aspecto da lesão e à topografia das lesões. Foram realizadas biópsias incisionais das lesões de pele em todos os cães, utilizando-se punch $6 \mathrm{~mm}$ para estabelecimento do diagnóstico definitivo. Os animais acometidos foram principalmente fêmeas, da 
POGgIANI, S.S.C. et al. Ceratose actínica em cães. PUBVET, Londrina, V. 6, N. 10, Ed. 197, Art. 1320, 2012.

raça Pit Bull americano, com idade média de 4,3 $( \pm 0,8)$ anos. O quadro clínico consistiu na presença de crostas, descamação, alopecia e pápulas, em abdômen ventral, flanco e parte medial de membros pélvicos. Piodermite secundária foi um achado comum. Os principais achados histopatológicos foram hiperplasia e displasia na epiderme, sem invasão da membrana basal.

Palavras-chave: cão, dermatologia, ceratose actínica

\title{
Actinic keratosis in dogs
}

\begin{abstract}
Actinic keratosis is a skin disease that affects dogs, mainly short-coated and white-haired skin ones. The main cause is cronically sun exposure, which leads to local and sistemically imunologic changes. The article shows 10 dogs with actinic keratosis. Breed, sex, age, lesion site and aspect were evaluated. Skin biopsies were performed in all dogs, using a $6 \mathrm{~mm}$ punch to establish the definitive diagnosis. The majority were female, American Pit Bull breed, with mean age of $4,3( \pm 0,8)$ years old. Crusts, scales, alopecia and papules were seen in ventral abdomen, flank, and medial thighs. Secondary infection was a common finding. Epidermal hyperplasia and dysplasia were seen, without basal membrane involvement.
\end{abstract}

Keywords: dog, dermatology, actinic keratosis

\section{INTRODUÇÃO}

A ceratose actínica é uma doença bem documentada no homem (ORTONNE, 2002; COCKERELL, 2003; LEBWOHL, 2003) e que também acomete cães (HARGIS et al., 1977; PAPADOGIANNAKIS et al., 2008) e gatos (FAVROT et al., 2009). As lesões são observadas em áreas cronicamente expostas ao sol e na 
POGGIANI, S.S.C. et al. Ceratose actínica em cães. PUBVET, Londrina, V. 6, N. 10, Ed. 197, Art. 1320, 2012.

maioria dos casos ocorrem em regiões menos pigmentadas e com poucos pêlos, como abdômen ventral e lateral e flanco (GROSS et al., 2005). Cães das raças Dálmata, American Staffordshire Terrier, Beagle, Basset Hound e Bull Terrier apresentam predisposição a lesões actínicas (SCOTT et al., 2001). As lesões ocorrem principalmente em cães mais velhos, mas a doença também foi observada em idade inferior a dois anos (GROSS et al., 2005).

O principal fator etiológico é a excessiva exposição à luz UV, que provoca conseqüências imunológicas locais e sistêmicas. Ocorrem alterações as funções e características morfológicas das células de Langerhans, além de influenciar a produção de citocinas na pele (LEBWOHL, 2003). O reconhecimento e processamento prejudicado de antígenos e uma resposta imune deficiente podem influenciar a susceptibilidade a neoplasias e infecções cutâneas (SCOTT et al., 2001). O estresse fotooxidativo provocado por raios UVA indiretamente causa mutações características no DNA (ácido desoxirribonucléico). Por outro lado, a radiação UVB age diretamente na formação de dímero de timina e transições $C \rightarrow T$ OU CC $\rightarrow$ TT no DNA e RNA. A ausência de mecanismos adequados de reparação nestas alterações no DNA representa o início das mutações nos ceratinócitos que podem progredir no desenvolvimento da ceratose actínica (STOCKFLETH \& KERL, 2006).

A exposição iatrogênica repetida à luz UVA em combinação ou não com psoralenos, raios-X ou radioisótopos também é considerada agente causal. Além disso, o papilomavírus atua como co-carcinógeno na etiopatogenia da ceratose actínica em humanos e estimula a proliferação epitelial em várias espécies animais (STOCKFLETH \& KERL, 2006; MUNDAY et al., 2007). Em humanos, existem outros fatores de risco, como por exemplo, dieta rica em gordura (LEBWOHL, 2003), imunossupressão crônica, exposição a arsênico e inflamação cutânea crônica (ULRICH et al., 2007). 
POGGIANI, S.S.C. et al. Ceratose actínica em cães. PUBVET, Londrina, V. 6, N. 10, Ed. 197, Art. 1320, 2012.

Em cães, o aspecto clínico é extremamente variável. As lesões iniciais caracterizam-se por placas eritematosas e espessas e são encontradas principalmente em abdômen ventral, flanco e parte medial de membros pélvicos. Em decorrência da cronicidade, as lesões variam de eritema focal com crostas e descamação, pápulas e máculas mal definidas, a placas e nódulos ceratóticos, firmes, com crostas escurecidas. Erosões e úlceras com crostas hemorrágicas podem ocorrer. Piodermite secundária com furunculose actínica são achados comuns e são oriundos de comedões actínicos. No cão, o diagnóstico diferencial clínico de lesões infiltrativas, profundas e severas incluem foliculite e furunculose bacteriana profunda e CCE (GROSS et al., 2005).

As alterações epidérmicas são variáveis e dependem do estágio da doença. Os principais achados são hiperplasia e displasia na epiderme. Quando estas ocorrem sem invasão da membrana basal, há ceratose actínica (GROSS et al., 2005). Outros achados incluem atipia da epiderme e do epitélio superficial do folículo piloso e hiperceratose, principalmente paraceratose (SCOTT et al., 2001). A displasia envolvendo todas as camadas da epiderme define o carcinoma in situ, ou doença de Bowen (BERMAN et al., 2006). Por outro lado, quando há penetração da derme, significa que o carcinoma de células escamosas já está instalado, o que pode ocorrer em lesões avançadas (GROSS et al., 2005).

Lesões iniciais apresentam melhora clínica com o uso de fotoprotetores e evitando-se exposição solar. Se houver prurido ou dor, glicocorticóides tópicos ou por via oral são benéficos. Lesões avançadas requerem a utilização de retinóides sistêmicos como isotretinoína, etretinato ou acetretina, criocirurgia ou remoção cirúrgica (SCOTT et al., 2001). Os objetivos deste trabalho foram avaliar os aspectos epidemiológicos de cães acometidos por ceratose actínica e descrever o quadro clínico observado. 
POGgIANI, S.S.C. et al. Ceratose actínica em cães. PUBVET, Londrina, V. 6, N. 10, Ed. 197, Art. 1320, 2012.

\section{MATERIAL E MÉTODOS}

Foram avaliados 10 cães com diagnóstico de ceratose actínica. Os animais foram atendidos no Serviço de Oncologia Veterinária do Hospital Veterinário "Governador Laudo Natel" da Faculdade de Ciências Agrárias e Veterinárias (FCAV) da Universidade Estadual Paulista (Unesp) "Júlio de Mesquita Filho", Câmpus de Jaboticabal. Os cães foram analisados em relação à raça, ao sexo, à idade, ao aspecto da lesão e à topografia das lesões. Após realização de exame físico, foram coletadas amostras para realização de exame parasitológico de raspado cutâneo e citologia das lesões. Foram realizadas biópsias incisionais das lesões de pele em todos os cães, utilizando-se punch $6 \mathrm{~mm}$. As amostras foram cuidadosamente enxutas para remover o sangue, colocadas com o lado da epiderme para baixo em um pedaço de madeira para minimizar os artefatos induzidos pelo encolhimento, e fixadas em formalina tamponada por fosfato a $10 \%$, respeitando-se o mínimo de dez partes de formalina para uma parte de tecido, durante 24 horas. Foram realizados cortes de $3 \mu \mathrm{m}$ da amostra parafinada para coloração pela Hematoxilina-eosina (H.E.). Utilizaram-se os critérios histopatológicos de acordo com GROSS et al. (2005) para estabelecer o diagnóstico de ceratose actínica.

\section{RESULTADOS E DISCUSSÃO}

As dermatopatias provocadas pela exposição excessiva à radiação solar são amplamente pesquisadas em medicina humana (CARPENTER et al., 2004; OH et al., 2004; BERMAN et al., 2006; SILVA et al., 2006; RÖWERT-HUBER et al., 2007; ULRICH et al., 2007). Entretanto, o mesmo não ocorre em medicina veterinária, apesar da elevada incidência destas doenças (ALMEIDA et al., 2001; PRONOVOST et al., 2004; TAMMENHAIN et al., 2008; FAVROT et al., 2009). 
POGGIANI, S.S.C. et al. Ceratose actínica em cães. PUBVET, Londrina, V. 6, N. 10, Ed. 197, Art. 1320, 2012.

Os cães das raças Dálmata, American Staffordshire Terrier, Beagle, Basset Hound e Bull Terrier apresentam predisposição a lesões actínicas (SCOTT et al., 2001). Entretanto, os cães da raça Pit Bull americano foram os mais acometidos neste estudo, seguidos por aqueles da raça Boxer, Dogo Argentino, Dogue Alemão e Bull Terrier. Este dado corrobora com dados de autores brasileiros, que observaram alta incidência da ceratose actínica em cães da raça Pit Bull americano (TAMMENHAIN et al., 2008). A maior frequência observada nestes animais pode ser explicada pelo aumento da população desta raça nos últimos anos somado a excessiva exposição ao sol relatada pelos proprietários. Esta última foi o principal fator de risco no desenvolvimento da ceratose actínica.

A média de idade dos cães acometidos por ceratose actínica foi de 4,3 $( \pm 0,8)$. Isso se contrapõe aos valores citados por GROSS et al. (2005), que afirmaram que as lesões ocorrem principalmente em cães mais velhos. Estes dados indicam que esta população sofreu uma exposição precoce aos fatores de risco, em especial à luz solar, resultando no desenvolvimento da doença ainda na fase adulto-jovem, o que pode culminar na redução na expectativa de vida destes cães.

Houve maior frequência de fêmeas em relação aos machos (7 fêmeas e 3 machos). Todos os cães possuíam pelame curto e de coloração branca em cerca de $90 \%$ da superfície corporal, o que confirma a predisposição de animais com estas características citada por HARGIS et al. (1977) e GROSS et al. (2005). Essa predileção pode ser justificada pela ausência das propriedades fotoprotetoras da melanina e pela redução da proteção da pele em vista do comprimento curto dos pêlos.

Além disso, a maioria dos cães (8/10) apresentou dermatopatias crônicas, como piodermites, foliculites bacterianas e demodiciose. Estas afecções são acompanhadas por inflamação da pele. É possível que a inflamação cutânea 
POGgIANI, S.S.C. et al. Ceratose actínica em cães. PUBVET, Londrina, V. 6, N. 10, Ed. 197, Art. 1320, 2012.

crônica seja um fator de risco importante, conforme citado por ULRICH et al. (2007).

Apenas dois cães de cada grupo foram submetidos ao uso prolongado de prednisona, o que pode resultar em imunossupressão. Entretanto, não foi feito um estudo sobre a imunocompetência destes cães. Logo, não é possível inferir se a imunossupressão crônica foi um fator de risco nesses cães, como estabelecido em humanos portadores de ceratose actínica, segundo ULRICH et al. (2007).

As lesões dermatológicas foram variáveis (Figura 1 e 2 ). Alguns cães apresentaram eritema, pápulas, alopecia e descamação, conforme descrito por SCOTT et al. (2001). Os comedões foram frequentes, observados principalmente em região abdominal ventral e tórax lateral e nos casos em que a pele estava crostosa e xerótica. Outros cães apresentaram quadros mais severos, caracterizados por piodermite superficial e profunda, com a presença de crostas, colaretes epidérmicos e pústulas, o que macroscopicamente lembrava pênfigo foliáceo. Este quadro clínico foi reconhecido também por PAPADOGIANNAKIS et al. (2008).

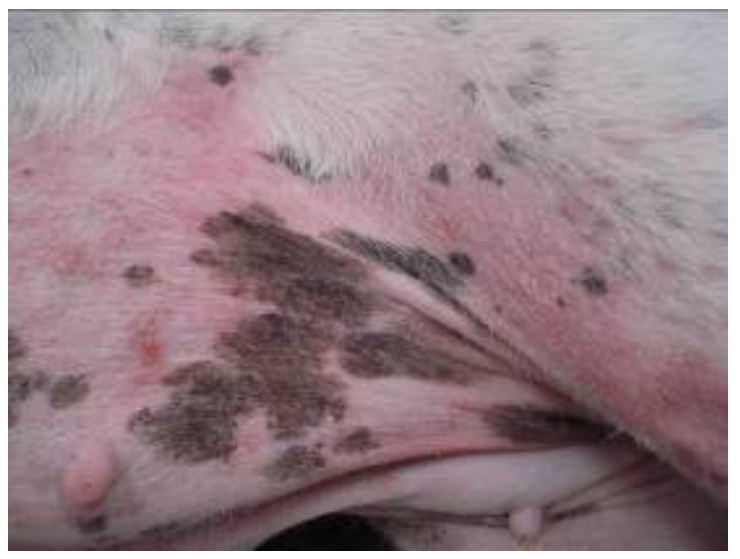

Figura 1. Ceratose actínica. Eritema, alopecia e crostas em região abdominal ventral. Fêmea, 4 anos, Pit Bull americano.

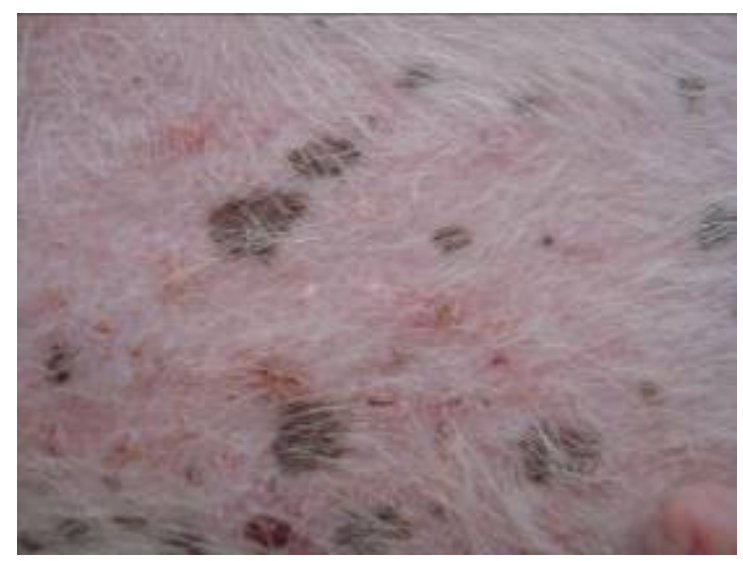

Figura 2. Ceratose actínica. Foliculite bacteriana superficial em região abdominal ventral. Fêmea, 4 anos, Pit Bull americano. 
POGgiani, S.S.C. et al. Ceratose actínica em cães. PUBVet, Londrina, V. 6, N. 10, Ed. 197, Art. 1320, 2012.

Além das principais regiões acometidas por ceratose actínica, conforme citado por GROSS et al. (2005), que incluem abdômen ventral, flanco e membros pélvicos, os cães apresentaram lesões também em bolsa escrotal, tórax lateral e em plano nasal. Em um estudo retrospectivo realizado por outros autores, o plano nasal foi o local mais frequente em cães da raça Pit Bull americano acometidos por ceratose actínica (TAMMENHAIN et al., 2008). Nossos resultados foram contrários, uma vez que apenas dois cães foram afetados nesta região. Embora a região lateral do tórax não seja a mais comumente afetada por esses processos dérmicos, em nosso estudo, optou-se pela coleta das amostras para controle desta região, pois os animais viviam em canil com piso de plástico e apresentavam eritema discreto na pele da região abdominal ventral por contato com essa superfície.

Os achados histopatológicos encontrados nos cortes de ceratose actínica foram condizentes com os descritos por GROSS et al. (2005). Na epiderme observou-se hiperplasia, acompanhada por hiperceratose e/ou paraceratose (Figura 3). Estes autores descrevem a alteração da arquitetura normal, o que neste estudo foi evidenciado pela perda da polaridade dos ceratinócitos, pleomorfismo celular moderado e desorganização das camadas da epiderme (Figura 4).

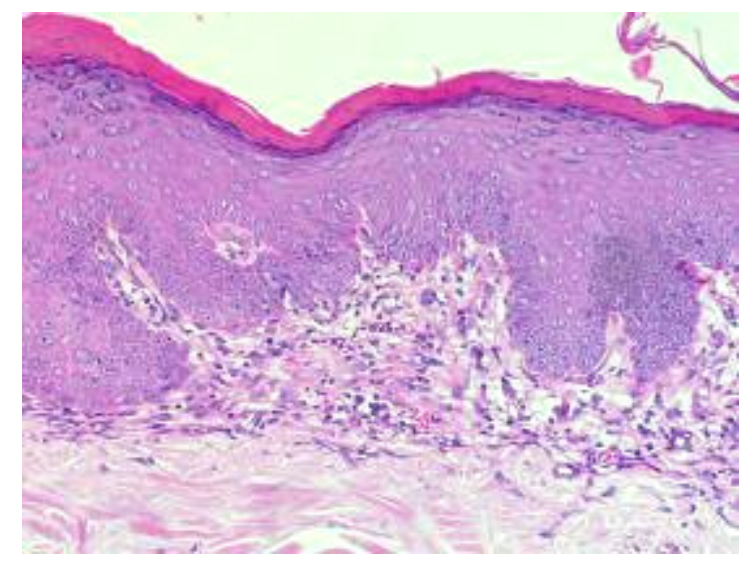

Figura 3. Ceratose actínica. Epiderme exibe hiperplasia irregular, com formação de cristas e paraceratose compacta confluente. Coloração: H.E. 200X. 
POGGIANI, S.S.C. et al. Ceratose actínica em cães. PUBVET, Londrina, V. 6, N. 10, Ed. 197, Art. 1320, 2012.

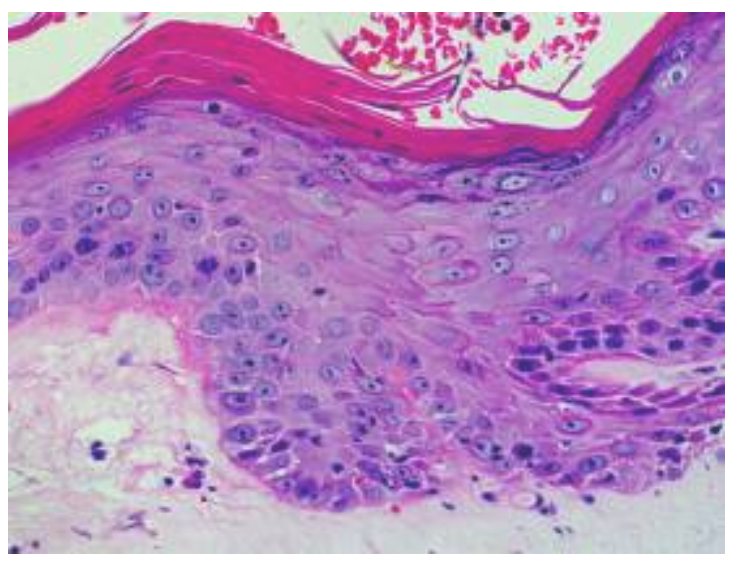

Figura 4. Ceratose actínica. Pleomorfismo celular, perda da polaridade dos ceratinócitos e desorganização das camadas da epiderme. Coloração: H.E. 400X.

Nos anexos cutâneos notaram-se folículos pilosos apresentando dilatação cística infundibular por hiperceratose e em alguns casos também haviam colônias bacterianas com proliferação de neutrófilos caracterizando uma infecção secundária, o que condiz com as afirmações de GROSS et al. (2005), de que a infecção bacteriana secundária é decorrente de comedões actínicos. Observou-se degeneração do colágeno no tecido conjuntivo frouxo localizado na derme e de fibras elásticas, evidenciando o quadro de elastose solar, o que admite o papel da injúria solar na etiologia da doença, uma vez que as alterações elastóticas na pele são consideradas o principal indicador de exposição solar cumulativa na derme (KLIGMAN \& SAYRE, 1991).

\section{CONCLUSÕES}

De acordo com os dados epidemiológicos obtidos em nosso estudo, é possível concluir que a ceratose actínica acomete os animais em faixa etária jovem, o que pode reduzir a sobrevida destes cães caso ocorra a progressão para carcinoma de células escamosas. Os autores destacam a importância do clínico reconhecer os dados epidemiológicos, referentes principalmente a raça e cor de pelagem, pois o quadro clínico com frequência se assemelha a uma piodermite superficial. 
POGgIANI, S.S.C. et al. Ceratose actínica em cães. PUBVET, Londrina, V. 6, N. 10, Ed. 197, Art. 1320, 2012.

\section{REFERÊNCIAS ${ }^{1}$}

ALMEIDA, E. M. P.; PICHÉ, C.; SIROIS, J.; DORÉ, M. Expression of cyclo-oxygenase-2 in naturally occuring squamous cell carcinomas in dogs. The Journal of Histochemistry \& Cytochemistry, St-Hyacinthe, v. 49, n. 7, p. 867-875, 2001.

BERMAN, B.; BIENSTOCK, L.; KURITZKY, L.; MAYEAUX, E. J.; TYRING, S. K. Actinic keratoses: sequelae and treatments. The Journal of Family Practice, Miami, v. 55, suppl., p. 1-8, 2006.

CARPENTER, P. M.; LINDEN, K. G.; MCLAREN, C. E.; LI, K-T.; ARAIN, S.; BARR, R. J.; HITE, P.; SUN, J. D.; MEYSKENS Jr, F. L. Nuclear morphometry and molecular biomarkers of actinic keratosis, sun-damaged, and nonexposed skin. Cancer Epidemiology, Biomarkers \& Prevention, Orange, v. 13, n. 12, p. 1996-2002, 2004.

COCKERELL, C. J. Pathology and pathobiology of the actinic (solar) keratosis. British Journal of Dermatology, Dallas, v. 149, suppl. 66, p. 34-36, 2003.

FAVROT, C.; WELLE, M.; HEIMANN, M.; GODSON, D. L.; GUSCETTI, F. Clinical, histologic, and immunohistochemical analyses of feline squamous cell carcinoma in situ. Veterinary Pathology, Zurich, v. 46, n. 1, p. 25-33, 2009.

GROSS, T. L.; IHRKE, P. J.; WALDER, E. J.; AFFOLTER, V. K. Skin diseases of the dog and cat: clinical and histopathologic diagnosis. Oxford: Blackwell, 2005. 932 p.

HARGIS, A. M.; THOMASSEN, R. W.; PHEMISTER, R. D. Chronic dermatosis and cutaneous squamous cell carcinoma in the beagle dog. Veterinary Pathology, v. 14, n. 3, p. 218-228, 1977.

KLIGMAN, L. H.; SAYRE, R. M. An action spectrum for ultraviolet induced elastosis in hairless mice: quantification of elastosis by image analysis. Photochemistry and Photobiology, Philadelphia, $\mathrm{v}$. 53, n. 2, p. 237-242, 1991.

LEBWOHL, M. Actinic keratosis: epidemiology an progression to squamous cell carcinoma. British Journal of Dermatology, New York, v. 149, suppl. 66, p. 31-33, 2003.

MUNDAY, J. S.; KIUPEL, M.; FRENCH, A. F.; HOWE, L.; SQUIRES, R. A. Detection of papillomaviral sequences in feline Bowenoid in situ carcinoma using consensus primers. Veterinary Dermatology, Palmerston North, v. 18, n. 4, p. 241-245, 2007.

ORTONNE, J-P. From actinic keratosis to squamous cell carcinoma. British Journal of Dermatology, Nice, v. 146, n. 61, p. 20-23, 2002.

PAPADOGIANNAKIS, E.; KONTOS, V.; FRANGIA, K. A case of canine squamous cell carcinoma secondary to solar keratosis (actinic carcinoma in situ). Journal of the Hellenic Veterinary Medical Society, Athens, v. 59, n. 1, p. 64-70, 2008.

PRONOVOST, N.; SUTER, M. M.; MUELLER, E.; SIROIS, J.; DORÉ, M. Expression and regulation of cyclooxygenase-2 in normal and neoplastic canine keratinocytes. Veterinary and Comparative Oncology, St. Hyacinthe, v. 2, n. 4, p. 222-233, 2004.

RÖWERT-HUBER, J.; PATEL, M. J.; FORSCHNER, T.; ULRICH, C.; EBERLE, J.; KERL, H.; STERRY, W.; STOCKFLETH, E. Actinic keratosis is an early in situ squamous cell carcinoma: a proposal for reclassification. British Journal of Dermatology, Berlin, v. 156, suppl. 3, p.8-12, 2007.

\footnotetext{
${ }^{1}$ ABNT - NBR 6023 ago. 2002
} 
SCOTT, D.; MILLER, W. H.; GRIFFIN, C. E. Small animal dermatology. 6 ed. Philadelphia: Saunders, 2001. 1528p.

SILVA, T. A.; COELHO, G.; BOCCA, A. L.; CAVALCANTE NETO, F. F. Expression of apoptotic, cell proliferation regulatory, and structural proteins in actinic keratosis and their association with dermal elastosis. Journal of Cutaneous Pathology, Distrito Federal, v. 34, n. 4, p. 315-323, 2006.

STOCKFLETH, E.; KERL, H. Guidelines for the management of actinic keratoses. European Journal of Dermatology, Berlin, v. 16, n. 6, p.599-606, 2006.

TAMMENHAIN, B.; FARIAS, M. R.; OBLADEN, A.; WERNER, J. Estudo retrospectivo da dermatite actínica em cães da raça pit bull terrier. In: CONGRESSO BRASILEIRO DA ASSOCIAÇÃO NACIONAL DE CLÍNICOS VETERINÁRIOS DE PEQUENOS ANIMAIS, 29., 2008, Maceió. Anais..., p.1-3.

ULRICH, M.; MALTUSCH, A.; RÖWERT-HUBER, J.; GONZÁLEZ, S.; STERRY, W.; STOCKFLETH, E.; ASTNER, S. Actinic keratoses: non-invasive diagnosis for field cancerisation. British Journal of Dermatology, Berlin, v. 156, suppl. 3, p. 13-17, 2007. 